\title{
Understanding terra-cotta distress: Evaluation and repair approaches
}

Received (in revised form): 26th October, 2006

\section{Edward A. Gerns}

joined WJE in 1990 and has served as project manager and project architect/engineer on assignments related to the investigation and repair of deteriorated conditions in existing buildings. He has performed evaluations of brick, terra-cotta, and stone masonry, assessed causes of collapse or distress in existing cladding systems, and has inspected numerous structures damaged by wind, ice, snow, and fire. He has conducted condition surveys and overseen preparation of repair documents for contemporary and historic buildings and structures.

\section{Joshua Freedland}

joined WJE in 2001 and has been involved in many architectural preservation and materials conservation projects. His work has included materials analysis, historic research, building documentation, facade investigations, condition surveys, and construction observations. His work has included a variety of materials including brick, terra-cotta, stone, mortar, stucco, scagliola, architectural metals, and wood. In addition, he has extensive experience with the preservation of historic finishes and facade cleaning.

Correspondence: Edward A. Gerns, Wiss, Janney, Elstner Associates, Inc., 120 North LaSalle, Suite 2000, Chicago IL, USA; Tel: +1 312372 0555; Fax: +1 312372 0873; E-mail: egerns@wje.com

\begin{abstract}
This paper will provide a brief history of terra-cotta veneer systems in general and specifically representative examples of terra-cotta-clad building systems in the United States. Through case studies, various types of distress, the causes of distress, and repair techniques of the distress will be discussed. Distress in terra-cotta facades often manifests as cracking or displacement of terra-cotta units. More than other modern curtain wall systems, terra-cotta is a hybrid system and distress may result from a number of causes. Common repairs including replacement, removal, and reinstallation, and in situ through face pinning may all be appropriate depending on the cause of distress. The underlying cause of distress must be understood, so that a durable repair and appropriate maintenance programme can be established.
\end{abstract}

Journal of Building Appraisal (2007) 2, 282-293. doi:10.1057/palgrave.jba.2950049

\section{Keywords:}

terra-cotta, skyscrapers, restoration, distress, repair

\section{INTRODUCTION}

Distress in terra-cotta facades often manifests as cracking or displacement of terra-cotta units. More than other modern curtain wall systems, terra-cotta is a hybrid system and distress may result from a number of causes. Common repairs including replacement, removal and reinstallation, and in situ through face pinning may all be appropriate depending on the cause of distress. The underlying cause of distress must be understood, so that a durable repair and appropriate maintenance programme can be established.

\section{HISTORICAL BACKGROUND}

Throughout the 19th and the early 20th centuries, innovations in structural engineering, construction materials, and construction techniques allowed for the construction of taller buildings. Economic and social factors, including increased density and mechanisation, 
provided the economic incentive to construct these new buildings. In order to build taller buildings quickly, the amount and weight of facade materials decreased, and mass produced replicated ornament replaced custom-carved facade elements. The architectural aesthetic, innovations in structural engineering, economic incentives, and material development of the time incorporated the new materials and repetitive decorative features leading to a new building type — The Skyscraper.

Prior to the $1870 \mathrm{~s}$, the exterior walls of buildings functioned as both the building's structural system and the enclosure for the interior space. During this era, masonry walls were monolithic. The load-bearing capacity of the buildings depended on the thickness of the exterior walls and the load capacity of the underlying soil. Typically, the walls were built with face brick or stone on the exposed surface and common brick for the interior or backup wythes of masonry. The wythes of these walls were tied together by uniformly distributed individual units or headers, turned perpendicular to the plane of the wall and spanning between adjacent wythes.

The industrial revolution of the late 19th century led to the introduction of steel as a building material. With the ability to economically manufacture steel shapes, the skeletonframe building system soon developed. Steel-frame buildings became common practice in the construction industry because of their economy, scale, and speed of construction compared to load-bearing masonry buildings. Skeleton construction allowed exterior walls to be designed 'primarily for the purpose of excluding [sic] the elements, and to provide opportunity for architectural treatment' (Voss and Varney, 1927).

\section{TERRA-COTTA MATERIAL AND STRUCTURE}

Terra-cotta is a fired ceramic material used since ancient times as architectural ornament. Henry Tomlan of Worcester, Massachusetts, first popularised moulded terra-cotta units for architectural applications in the United States by the late 1840s (Tunick, 1997). Terra-cotta weighs approximately $1060-1390 \mathrm{~kg} / \mathrm{m}^{2}$ (Kidder and Parker, 1956). Water absorption values typically range from 6 to 14 per cent by weight. Compressive strength typically ranges from 345 to $1380 \mathrm{~N} / \mathrm{cm}^{2}$ depending on web orientation (Kidder and Parker, 1956).

Terra-cotta units were first used on buildings for roofing, flooring, and sculpturing. Subsequently, builders used terra-cotta as a substitute for natural stone. Terra-cotta was less expensive to manufacturer than hand-carved stone for the repetitive ornament in skyscrapers, since multiple identical units could be produced from a single model and mould. It allowed for increased and elaborate ornamentation in commercial structures as can be illustrated dramatically by the work of Louis Sullivan (Figure 1).

For manufacturing purposes, terra-cotta units measured usually about $45.7 \mathrm{~cm} \mathrm{long}$, but generally no longer than $61.0 \mathrm{~cm}, 15.2-30.5 \mathrm{~cm}$ deep; the height was determined by the character of the piece. Units are comprised of an outer shell braced with intermittent webs to prevent warping of the unit during firing and to add strength. Spacing of the webs created cells. The distance between webs was typically not greater than $15 \mathrm{~cm}$ (Kidder, 1905). Bricks and mortar filled the cells in the terra-cotta units from behind to create a monolithic wall. Pieces installed within the plane of the wall are referred to as balanced pieces, and pieces projecting from the wall are referred to as unbalanced pieces and required additional anchorage support during installation.

Compared to stone, the lighter weight of terra-cotta units allowed architects to introduce cornices and other projecting building elements. In addition, designers used terra-cotta for spandrels, sills, jambs, and heads. Further, advances in chemical 
engineering allowed designers to use textures, colours, and finishes unavailable in natural stone such as gold lustre finishes or elaborate polychromatic finishes (Figure 2).

These new cladding systems led to the development of an anchorage system to attach the terra-cotta units to the building structure, to provide lateral stability and vertical support of each unit and to facilitate the efficiency and speed of construction. Supplemental steel framing was added to the structural building frame for support. The structural elements could be located directly above the hung units, embedded within the brick masonry, or behind additional terra-cotta units within the system (Figure 3). This anchorage, typically, consisted of bent steel or iron bars installed into the top of the unit or through a preformed hole in a web. Generally, projecting units had only the portion of the units within the wall surface filled with brick and mortar to keep the centre of gravity of the unit as close to the face of the wall as possible and to transfer loads through the units. Metal hooks, bars, and rods were not only used to resist the over-turning moment from gravity loads, but also allowed construction of the wall to proceed before the mortar cured (Figure 4). Hung units such as window heads were supported by horizontal bars - inserted through holes in the webs - and by J-hooks. The J-hooks are anchored to structural steel elements such as shelf angles or spandrel beams.

The exterior masonry was assembled around the steel frame, and the terra-cotta units were packed solid with bricks and mortar from behind as they were installed. The cladding also provided fire protection for the steel frame.
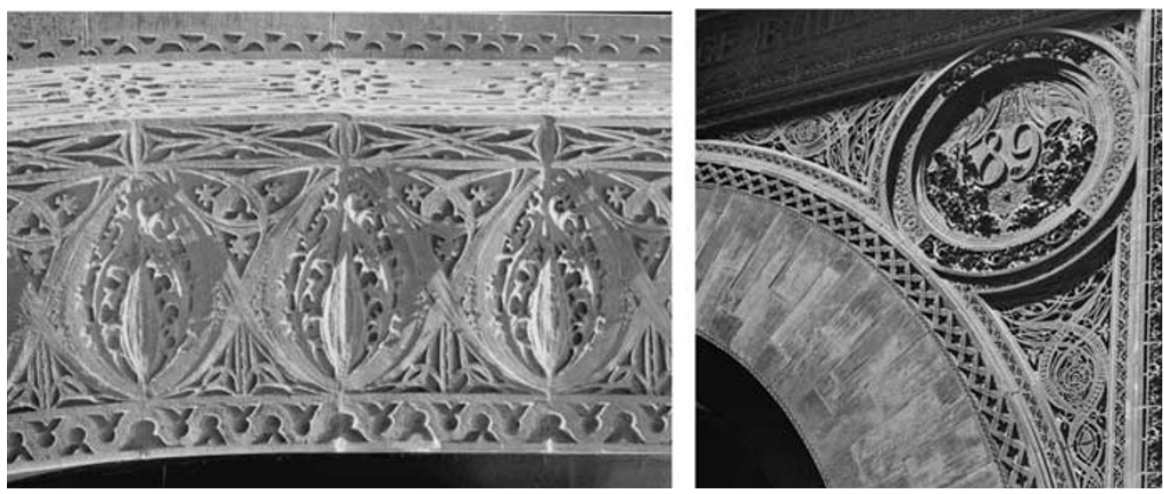

Figure I: Ornamental terra-cotta from Louis Sullivan designed Chicago Stock Exchange. Source: Historic American Building Survey
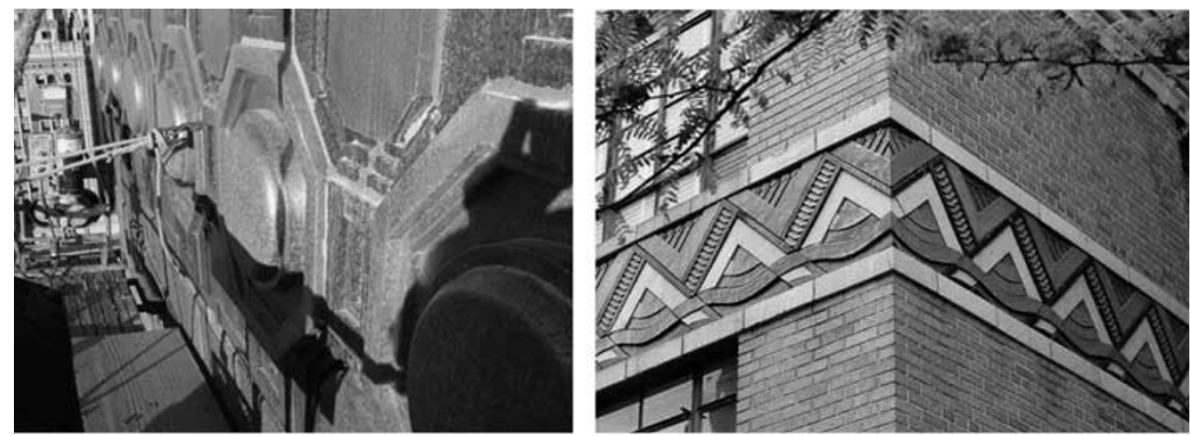

Figure 2: Terra-cotta with gold lustre finish (left) and polychromatic finish (right) 

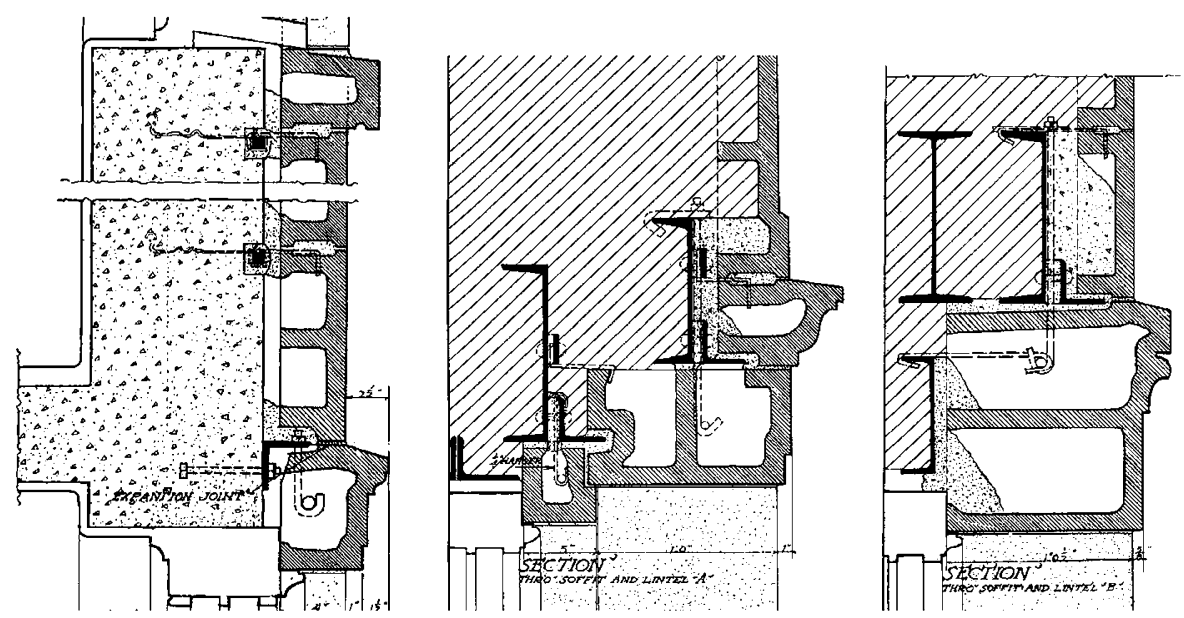

Figure 3: Representative terra-cotta details of window heads. Source: NTCS (1927)
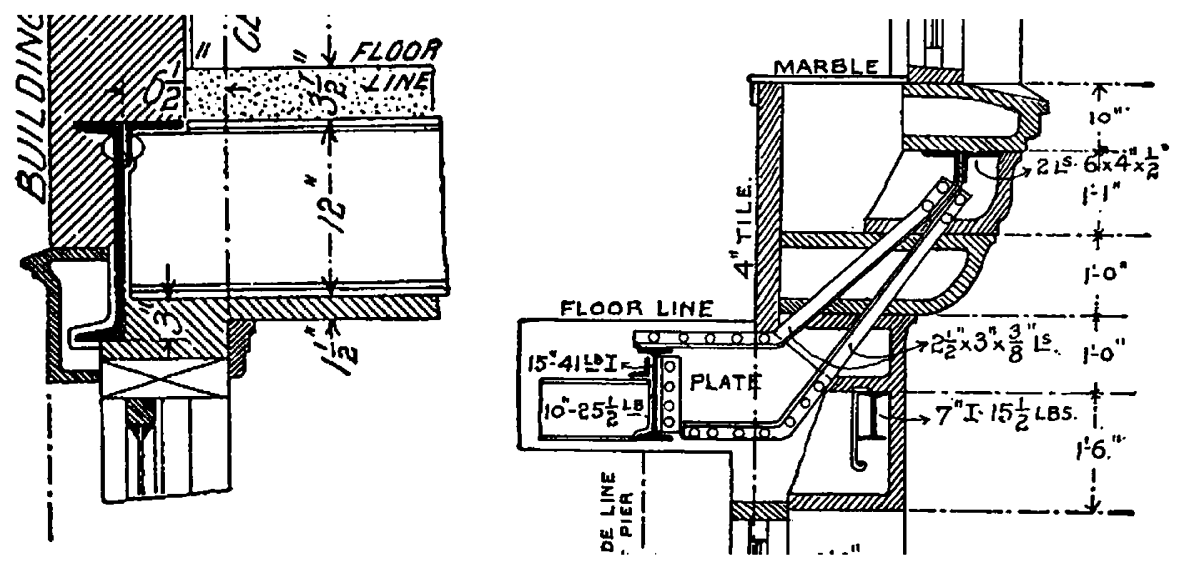

Figure 4: Typical details of notched terra-cotta units. Source: Birkmire (1905)

\section{DECAY MECHANISMS}

Typically, terra-cotta is a very durable material and may perform well in an exterior environment; most of the decay mechanisms of terra-cotta facades are a result of deterioration of the system rather than deterioration of the terra-cotta material (Figure 5). The main mechanisms, which cause deterioration of terra-cotta cladding systems, include moisture, thermal cycling, and built-up compressive forces. Water inevitably enters all building facades. The amount of water entering the system typically accelerates as materials deteriorate and stresses accumulate.

Prior to the 1950s, architectural design did not typically accommodate thermal cycling in exterior cladding systems. Physical properties of materials, colour, and exposure all affect the interaction between adjacent materials. Thermal cycling on the wall systems are difficult to predict, because of the complexity of the structure and materials within modern wall systems. Temperature cycling related to seasonal and daily temperature changes may cause thermal cracking either in the terra-cotta units, the mortar, or the 

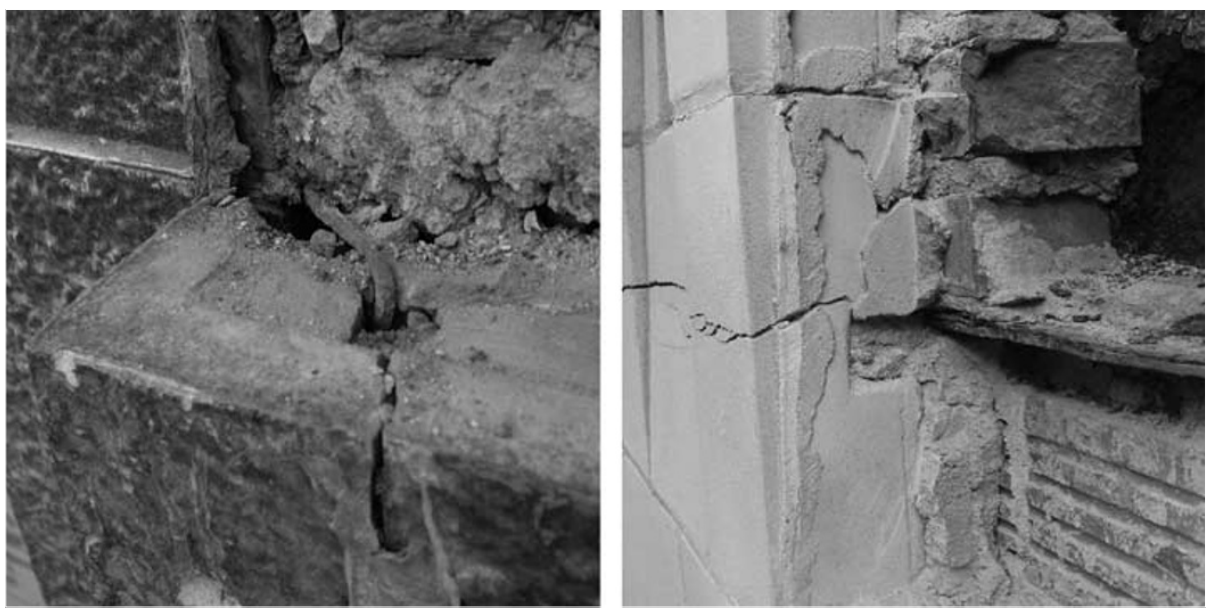

Figure 5: Representative distress of terra-cotta cladding. Cracking at lateral tie (left) and cracking at shelf angle location (right)

terra-cotta-mortar interface, which allows additional water to enter the cladding system and accelerate deterioration.

Terra-cotta, a fired clay product, undergoes a permanent expansion in the first decades of service. This expansion was not typically provided for in historic construction and may lead to the accumulation of compressive forces, additional cracking, and subsequent water infiltration. Further, the steel frame of the building may shrink or creep under load exacerbating the expansion of the terra-cotta cladding material.

Like earlier monolithic masonry facades, early masonry veneer walls rely on the mass of the masonry to absorb the moisture that enters the wall system. These same systems allow water to evaporate and leave the wall system.

Water infiltration contributes to the corrosion of embedded steel elements. Corrosion of iron has long been recognised as a potential problem. The incorporation of iron into masonry construction and subsequent corrosion-related distress has resulted in dramatic changes in the construction and detailing of cladding systems to address water infiltration and corrosion.

As the steel elements oxidise, corrosion scale forms that occupies a volume between four and ten times the volume of the original uncorroded steel. The forces resulting from the confined corrosion scale of the embedded steel elements causes visible and concealed distress in terra-cotta. Numerous methods of limiting corrosion have been employed throughout history to protect ferrous material including boiling the element in tallow, covering it with pitch or varnish, or galvanising it with molten tin or zinc. Occasionally, non-ferrous metals, such as bronze, were used as embedded anchors to limit the risk for damage from corrosion.

\section{THE NATURE OF DISTRESS}

Terra-cotta cracks when forces result in strain that produce stresses exceeding its capacity. Historically, veneer systems were designed empirically and derived more from the limitations of the materials, construction techniques, and aesthetics than service conditions. The increasing size of buildings, the limited understanding of certain material phenomena, and the lack of subsequent maintenance have resulted in failures of historical terra-cotta-cladding systems. The most visible indication of distress of terra-cotta units are cracked units. 


\section{Horizontal cracking}

Horizontal cracks most often form in hung units, roughly corresponding to location of the supporting bar. In notched units, cracks often propagate at the location of the notch (Figure 6). This cracking may be the result of the corrosion of the supporting shelf angle, from unaccommodated vertical stresses in the cladding system, or eccentric loading of the notched piece.

\section{Vertical cracking}

Vertical cracking is often an indication of systemic issues within the cladding system. Isolated vertical cracks within non-projecting piers or blank wall areas may be related to the corrosion of the lateral restraint bars. A crack within a pier or blank wall area may be related to a combination of corrosion of the restraint bars with unaccomodated expansion of the cladding system (Figure 7). Stresses resulting from restrained expansion tend to create either vertical cracks across multiple units or outward displacements at support locations. The vertical cracks form as a result of a weakness within the wall created by intermittent localised points of distress.
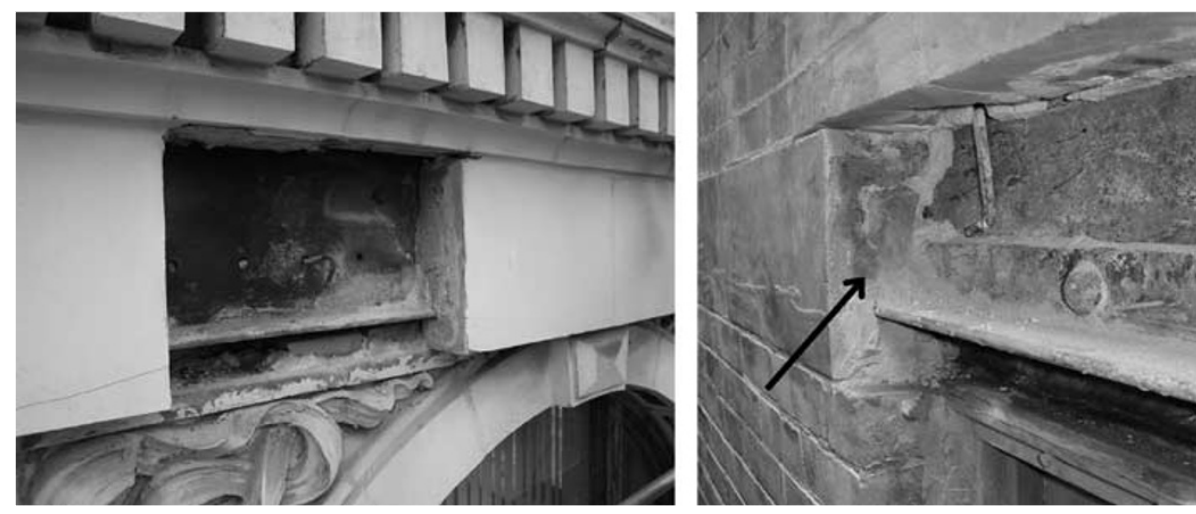

Figure 6: Horizontal cracking at shelf angle locations
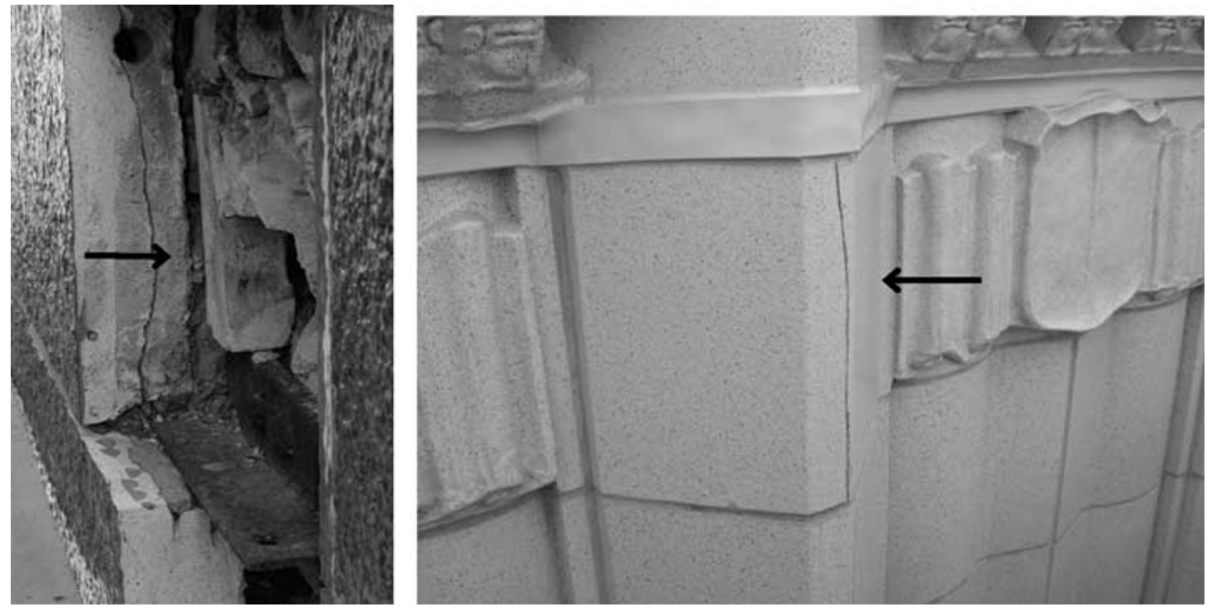

Figure 7: Vertical cracking within the plane of terra-cotta (left) and through the face (right) 
Buildings constructed without vertical expansion joints, to accommodate horizontal expansion, usually create joints in the form of vertical or step cracking near corners. The original design intent assumed that the cladding loads from each floor would be transferred into the main building structure by the 'relief' system of plates and angles at each floor. Strain measurements of the terra-cotta cladding of several skyscrapers built between 1910 and 1930 have revealed stresses well in excess of those conceptualised by the cladding design. The stresses in some instances have been found to exceed the anticipated stress by 100-200 times the idealised load path (Stockbridge, 1983). These stresses increase dramatically when the cladding accommodates corrosion scale from the steel support angles and lateral anchors.

\section{Diagonal cracking}

Diagonal cracking is much less common in terra-cotta cladding system and is often the result of units being subjected to multiple forces causing the units to be in a complex state of stress. The most common example of this complex state of stress is the end windowsill unit, which extends into the adjacent piers (Figure 8). The portion of the unit below the masonry opening has no significant prolonged stresses imposed, while the portion of the unit that extends into the pier may be subjected to significant compression forces from the units above. Inevitably, cracks will develop in these units roughly corresponding to the interface of the sill and pier. This is exacerbated since sill units are typically thinner than other units, and the bending caused by the force imposed by the pier is resisted in weak axis bending of the unit.

Diagonal cracking also occurs when lintel units extend into the pier area from the masonry opening for the window. Since these units are often substantially larger and deeper than the sills, the bending resistance is much higher. If the strains in the unit have not reached the point of fracturing the piece and depending on the finish on the terracotta, fine cracks within the terra-cotta glaze may mirror these opposing forces (Figure 9).

Although beyond the scope of this paper, cracking resulting from loads imposed by earthquake-related movements can also produce cracks indicative of compound stresses.

\section{Outward/horizontal displacements}

Displacement of cladding system is an indication of a systemic problem within the cladding system. Similar to vertical cracking, displacement is an indication of unaccomodated expansion. The displacements typically occur at shelf angle and restraint locations and may or may not be accompanied by vertical cracking (Figure 10). Some
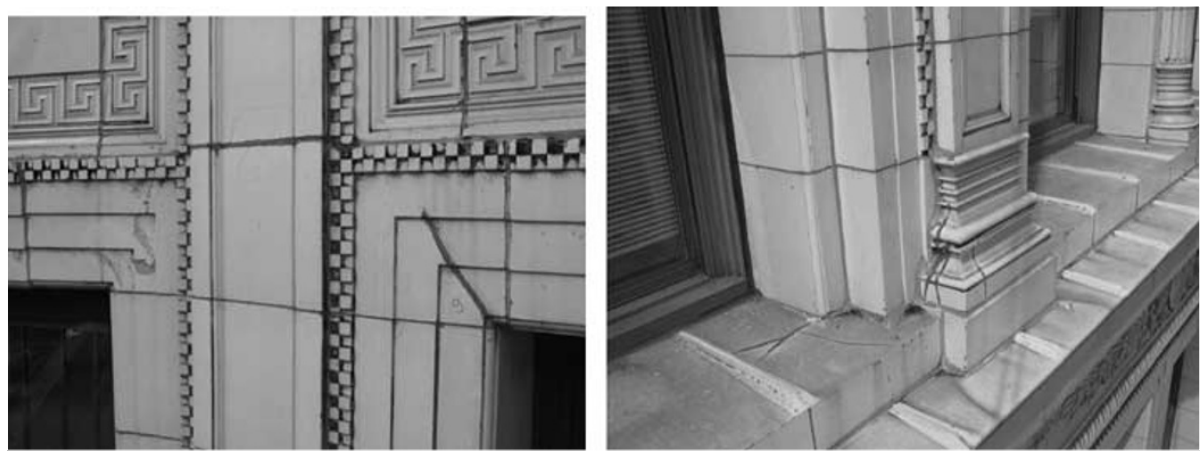

Figure 8: Example of diagonal cracking in terra-cotta 


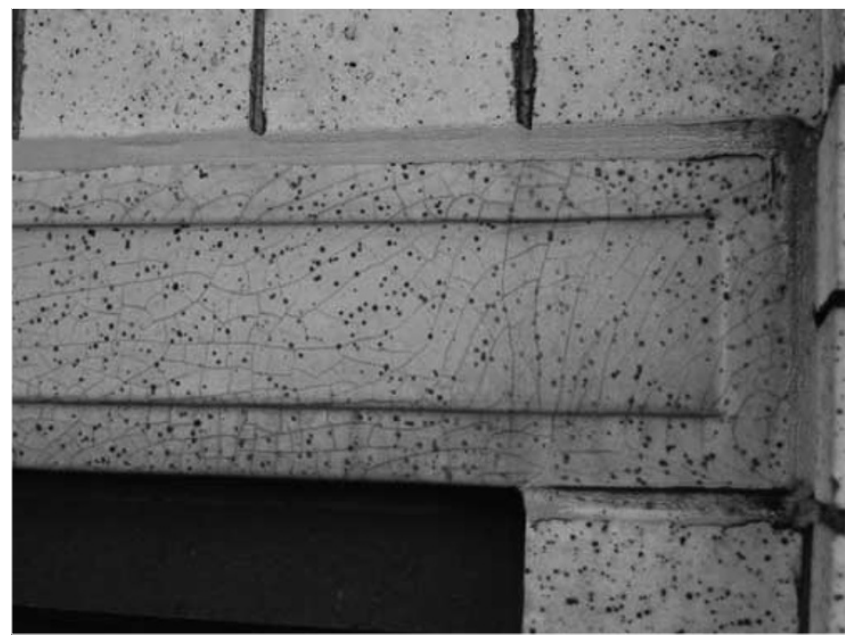

Figure 9: Fine cracks (crazing) reflecting stresses within terra-cotta unit
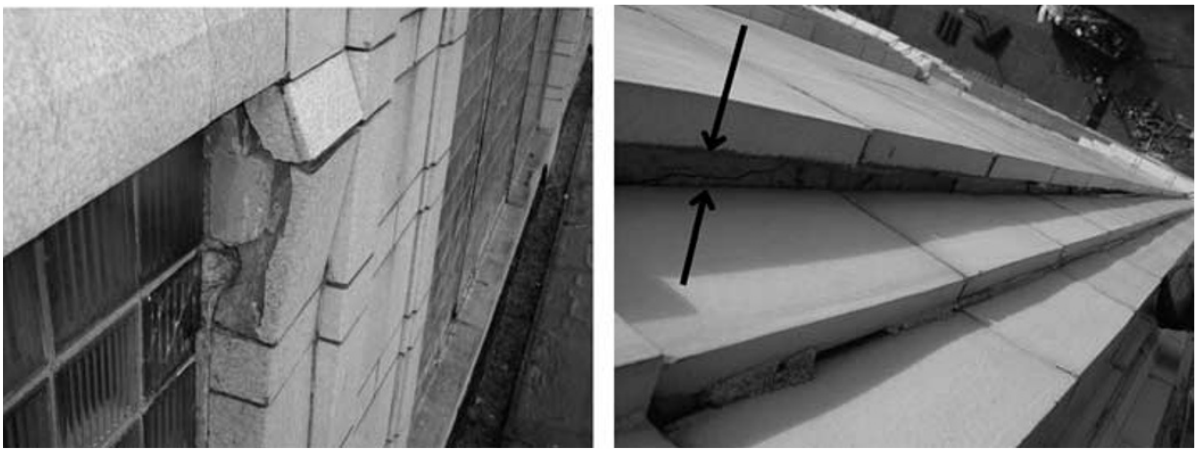

Figure 10: Examples of displaced individual terra-cotta units (left) and entire wall area (right)
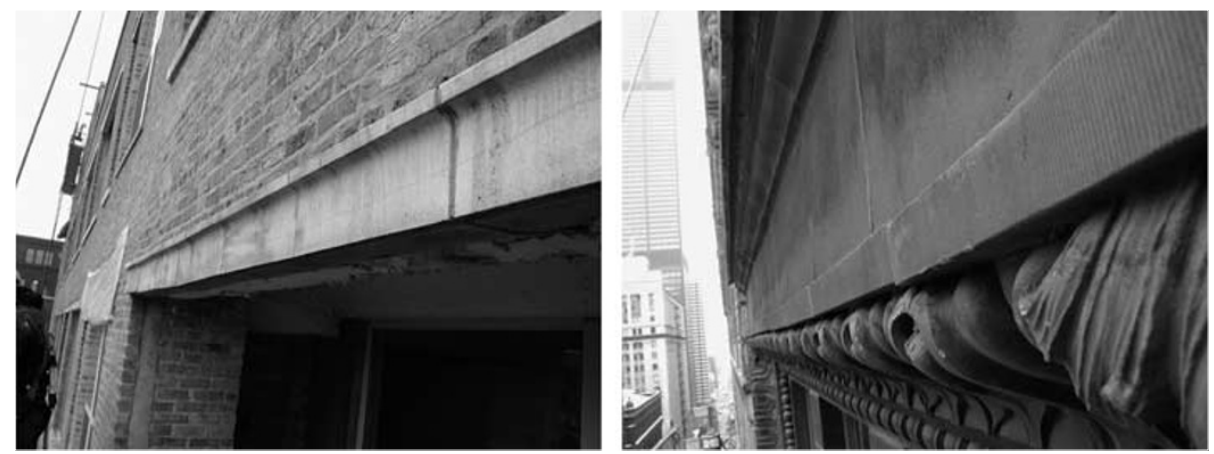

Figure I I: Vertical displacements of terra-cotta units over window openings

limited outward displacements may exist in wall systems, which may not be a significant issue. Measurements of the strain within the cladding system can be made to determine the severity of the condition. 


\section{Vertical displacements}

Vertical deflections of hung lintels above window areas are common with larger spans (Figure 11). Chicago-style windows, typical in historic terra-cotta buildings, combine large fixed units flanked by double hung windows, frequently result in masonry openings in excess of $5 \mathrm{~m}$. Support of the terra-cotta units above these openings were typically designed using empirical techniques. This resulted in sizing of steel-supporting members that were adequate in strength, but exceeded today's recognised deflection criteria for masonry. Accepted limits of deflection in contemporary structural design range from $1 / 600$ to $1 / 720$ of the span. Therefore, for a 5-m span, deflections should range from 6 to $8 \mathrm{~mm}$. These deflections have been measured by the authors in excess of $20 \mathrm{~mm}$. Deflection of this magnitude can result in premature deterioration of the mortar joints and potential corner edge spalling. Assuming the supporting structure is in serviceable condition, an increased maintenance cycle for the mortar should be anticipated, but no significant repairs are likely necessary. Localised distress, which may require repair, include spalling and cracking of individual units and displacement of larger areas. Corrosion of the steel support members may lead to a loss of cross-sectional area reducing the structural capacity of the steel element so that the element no longer adequately supports the required load.

\section{Other conditions}

While often the distress in terra-cotta cladding system follows these basic trends, there are typically unique conditions that must be understood on a case-by-case basis. These conditions may actually be a combination of several of the issues discussed above or unique conditions that require further evaluation. For instance, unusual load paths in the cladding or main building system can result in distress reflecting this condition. For instance, transfer beams clad in terra-cotta may exhibit cracks indicative of the load path.

\section{MAINTENANCE AND REPAIR OF EARLY CURTAIN WALL SYSTEMS}

In the 1950s, when significant deterioration became apparent, many historic terra-cottaclad buildings were demolished or projecting elements such as cornices were removed. This trend continued into the 1970s until the rise of the conservation movement. Today the appreciation of these buildings and the revitalisation of urban areas have led to greater emphasis on restoration and conservation of these buildings. As the early 20th century buildings continue to age, distress in the terra-cotta veneer buildings will continue. The need to economically and effectively maintain and repair these buildings will also increase. As embedded-steel members and anchors are exposed to moisture, the resulting corrosion and subsequent expansion damages the adjacent building materials.

Depending on the architectural, social, and historical significance of a building, the extent of conservation of the existing historic fabric may vary considerably. Historic masonry materials, particularly terra-cotta, may be very difficult and expensive to replicate. Depending on the condition and cause of distress within a terra-cotta unit it may be possible to repair rather than replace the unit.

Often the extent of deterioration of the supporting steel components or the resulting distress from the corroded elements necessitates the need for reconstructing portions of the facade. The reconstruction may require the replacement of the supporting steel and repair of the damaged terra-cotta units at other areas.

Fabrication of new flat non-decorative pieces is often more economical than repairing the existing pieces since these units are often manufactured using an extruded process 
rather than the traditional hand-packed technique. The cost of removal, repair, and reinstallation of non-decorative pieces may be greater than replacement. Depending on the significance of the building and conservation concerns, it may still be more desirable to repair and reuse pieces rather than replace them.

Fabrication of new matching replacement pieces in itself is a challenge that requires careful attention to detail to match the historic terra-cotta in colour, gloss, texture, and detail. Often a range of colours must be considered to mimic the range of the original finish. Therefore, it may be more desirable to spend additional time and cost to repair highly ornamental terra-cotta units that would require a unique and costly modelling and mould-making process.

A conventional and certainly rational approach to address terra-cotta repairs is to replicate the existing anchorage system in kind but replacing carbon steel components with corrosion-resistant materials such as stainless steel. While this approach is consistent with repair and conservation criteria, it may add considerable cost to the project because of the need to remove undistressed material adjacent to the distressed unit for the necessary access.

Several factors contribute to a conventional approach not always being the most costeffective. As previously discussed in traditional construction methods, the terra-cotta units were typically constructed integrally with the wall by keying the units into the wall with bricks set into the cells in the back of the units. Therefore, removal of existing units without causing damage is difficult, since the veneer system was effectively stitched together. If extreme care is not used, damage caused by unnecessary removal units will add additional potentially unnecessary costs and delays to the project.

In addition to removal, repair or replacement, and reinstallation, supplemental through face pins may be a viable and economically practical repair solution. Generally, there are two options for in situ anchor installation that are used in the United States. Given that the face shell of most terra-cotta units is generally between 2.5 and $3.2 \mathrm{~cm}$, careful attention of the drilling operation is critical to the integrity of any in situ anchor installation to minimise spalling of the back face of the terra-cotta. The more expensive option is the installation of a nylon or stainless steel screen that is then inserted into a hole and then filled with epoxy. A stainless steel rod is then inserted into the epoxy-filled screen. The performance of this system is dependant on the proper cleaning of the hole, mixing of epoxy, and engagement of the rod into face shell of the terra-cotta.

Another option is the installation of a self-tapping stainless steel anchor that is installed into an undersized hole. The anchor itself is wider than the hole so that as the anchor is set into the system, the threads of the anchor cut into the adjacent terra-cotta. The performance of this anchor is also dependant on the setting depth and engagement of the threads.

The following summary discusses how understanding the nature of the original construction and causes of the observed distress may allow for alternate repair techniques that satisfy safety concerns of the public, conservation concerns of the profession, and economic concerns of the owner.

\section{Treatment of distressed terra-cotta}

\section{Horizontal cracking}

Hung units, such as those typically found and lintels, with horizontal cracks generally cannot be adequately repaired in situ. Installing pins has limited applications and should be cautiously considered since the piece will rely almost entirely on the pins for support 
rather than the redundancy of the cladding system. Removal and repair of the units is an option that could be considered; however, the durability of the repair is critical due to the lack of redundancy of the hung portions and reliance on the repair itself. Often, these units are less ornate and it may be most efficient and offer a higher level of confidence of the repair to replace damaged units. Further, replacing these units typically requires dismantling fewer adjacent units. Once one of the hung units is removed, it is often efficient to remove the remaining units at lintel locations without damage. This allows for proactive coating of the steel support and replacement of the supporting hooks and anchors with a stainless steel to prevent future damage at this vulnerable location.

\section{Vertical cracking}

Vertical cracking may result in two independent units, which if properly supported vertically and horizontally can be repaired in situ. Since vertically cracking generally correlates to the lateral anchorage, it is prudent to assume that each portion of the unit is not laterally supported. As a result, repairs should include through face pinning followed by routing the crack to a uniform width and depth and installing a bond breaker and sealant or routing, and pointing the crack with mortar depending the anticipated future movement of the crack.

\section{Diagonal cracking}

The cracking of sill units is generally not a significant issue depending on the orientation and position of the crack. If the cracking has essentially resulted in creating two pieces rather than one, the crack can be effectively treated as a joint and repaired to minimise moisture infiltration. These types of cracks are generally best repaired by routing the crack to a uniform width and depth and installing a bond breaker material and sealant, since there will likely be continued movement between these now two separate terra-cotta units. Exploration openings at selected areas may help to determine if each portion of the terra-cotta unit still retains adequate lateral and vertical support. If multiple cracks exist in the unit, it may be necessary to add supplement pins to secure fragments or in extreme cases replace the unit. Replacing these units, typically, necessitates removal of the masonry material above the embedded portion of the sill to install a new piece.

If a lintel unit is cracked from the masonry opening into the pier area, resulting in two independent properly supported units, the piece may be repaired similar to a sill. This crack configuration results in the units acting as a flat arch with the cracked portion within the window area acting as a skewback to resist the thrust of the arch. If the crack extends vertically or diagonally into the masonry opening area above the window, the piece is likely wedged in place, but the resulting arch is much less stable. Depending on the configuration of supporting assembly, these pieces may still be properly supported, but likely should be replaced.

\section{Vertical displacements}

Vertical deflections of hung lintels above window areas are common with larger spans. Assuming the supporting structure is in serviceable condition, the units are properly supported, no repair or replacement may be necessary, but an increased maintenance cycle for the mortar should be anticipated.

\section{Outward/horizontal displacements}

Some limited outward displacements may exist in wall systems, which may not be a significant issue. Measurements of the strain within the cladding system should be made 
to determine the severity of the condition. As discussed earlier, most early skyscrapers made no accommodation for the accumulation of compressive stresses within the cladding system.

If displacement is not excessive, strain relief cuts can be made without reconstruction of large areas of the wall. Relief cuts will likely render the lateral anchorage for the units below the support ineffective. Therefore, supplemental lateral anchorage should be installed in these units. If the displacement results in the centre of gravity of the terra-cotta being outside the middle third of the unit, the units should be removed and reset. If the glaze exhibits fine cracks that do not extend into the bisque of the terra-cotta, no repair of the individual units may be necessary. It may be desirable, however, to provide strain relief to accommodate stresses within the wall.

\section{CONCLUSION}

To effectively repair a damaged terra-cotta facade, it is critical to understand the method of support, forces, or stresses in the unit as well as the cause of the distress. Generally, terra-cotta units are either hung, and therefore exposed to only self-weight-induced stresses, or integral to a wall system and subjected to the weight of the units above. The actual bearing force on a unit may vary considerably depending on the location, condition, and effectiveness of the intermediate relieving angles. Depending on the detailing and configuration of the units within the facade, a unit could also be partially hung and partially in bearing. These units are most common at the intersection of spandrel areas and piers and windowsills and piers.

Repairs, typically, include through face pinning, removal, repair, and resetting, or removal, replacement, and resetting. Installation of pins into masonry without removing the piece should not be considered a permanent repair in most situations. Without removing the cause of the distress, specifically the corroding steel, it is likely that additional cracking or displacement will occur following installation of the anchors.

One of the most important issues, that is frequently overlooked prior to performing restoration work, as well as, following a conservation project, is to establish a programme for future maintenance of the facade. For any building, a maintenance programme should include periodic inspections, repointing, and sealant replacement as well as other repairs necessary to minimise the potential for moisture infiltration. Future maintenance will also likely include future in situ pinning and replacement of additional terra-cotta units. If maintenance work is deferred, the lifecycle cost of maintaining the facade will be greatly increased and have the potential to become costly repairs or create life safety issues.

\section{References}

Birkmire, W. (1905) The Planning and Construction of High Office-Buildings, John Wiley and Sons, New York, NY, pp. $98-118$.

Kidder, F.E. (1905) 'Building construction and superintendence', Masons' Work, Part 1, 7th edn, William T. Comstock, New York, USA.

Kidder, F.E. and Parker, P (1956) Kidder-Parker Architects' and Builders' Handbook, 18th edn, John Wiley \& Sons, New York.

National Terra Cotta Society (NTCS) (1927) Terra Cotta, Standard Construction, M.B. Brown Printing \& Binding Company, New York, NY.

Stockbridge, J. (1983) Evaluation of Terra Cotta on In-Service Structures, ASTM STP 691: Durability of Building Materials and Components, Philadelphia.

Tunick, S. (1997) Terra-Cotta Skyline New York's Architectural Ornament, Princeton Architectural Press, New York. Voss, W.C. and Varney, E.A. (1927) 'Architectural Construction', Steel Construction, Vol. 2, Book 2, John Wiley \& Sons, Inc. New York, USA. 